\title{
Role of phosphorus in carbon matrix in desulfurization of diesel fuel using adsorption process
}

Mykola Seredych ${ }^{1}$, Zoe $\mathrm{Wu}^{2}$, Patrice Brender ${ }^{3}$, Conchi O. Ania ${ }^{3,4}$, Cathie Vix-Guterl ${ }^{3}$ and Teresa J. Bandosz ${ }^{1 *}$

\author{
${ }^{1}$ Department of Chemistry \\ The City College of New York \\ 160 Convent Ave \\ New York, NY 10031 \\ ${ }^{2}$ Stuyvensant HS \\ ${ }^{3}$ Institut de Science des Materiaux de Mulhouse, (CNRS LRC 7228), 15 rue Jean Starcky,68057 \\ Mulhouse, France \\ ${ }^{4}$ Instituto Nacional del Carbón (INCAR, CSIC), 33011 Oviedo, Spain
}

*Corresponding author. Tel.: (212) 650-6017; fax: (212) 650-6107. E-mail address: tbandosz@,ccny.cuny.edu (T.J. Bandosz) 


\begin{abstract}
Adsorptive removal of dibenzothiophene (DBT) and 4,6-dimethyldibenzothiophene (DMDBT) from model diesel fuel with $20 \mathrm{ppmw}$ total concentration of sulfur was investigated on polymerderived carbons with incorporated heteroatoms of oxygen, sulfur and phosphorus. The materials before and after exposure to model diesel fuel were characterized using adsorption of nitrogen, thermal analysis, potentiometric titration, XPS and elemental analysis. The selectivities for DBT and DMDBT adsorption were calculated with reference to naphthalene. The results indicated that the presence of phosphorus, especially in the form of pyrophosphates and $\mathrm{P}_{2} \mathrm{O}_{5}$, increases the capacity and selectivity for removal of dibenzothiophenes. It also affects the adsorption mechanism. Phosphorus suppresses oxidation reactions of DBT and DMDBT. Owing to a possible location of bulky phosphorus groups in pore with sizes between 10-30 $\AA$ thiophenic molecules are strongly adsorbed there via dispersive forces. Acidic environment also enhances adsorption via acid-base interactions. Physical adsorption mechanism and stability of surface make these carbons attractive candidates for thermal regeneration.
\end{abstract}

Keywords: dibenzothiophenes, model diesel fuel, activated carbon, P-functionalities, reactive adsorption 


\section{Introduction}

Because sulfur in diesel fuel contributes to environmental pollution and poisoning of automobile catalytic convertors increasing research efforts leading to reduction of sulfur content or its total removal from fuel have been reported. Scientific efforts focus on oxidation [1,2], photoxidation $[3,4]$ or adsorption [5-29]. The adsorption based methods applied activated alumina [7, 8], zeolites [9], and activated carbons [7, 10-29] as adsorbents. The results obtained on the latter materials seem promising $[12,22,26-28]$.

Numerous studies indicated that the oxidation of a carbon surface enhances their performance in the desulfurization process $[15,17,18,21-23,26,27]$ owing to acid-base interactions of thiophenes with acidic oxygen groups of activated carbons $[15,18,22,23,27]$. Presence of copper [16, 24], iron [24] or silver [29] compounds on the carbons was also shown as beneficial for the selectivity of separation. In such cases the reactive adsorption involving the oxidation of DBT and DMDBT to sulfoxides and sulfones was proposed [26-28]. These species, owing to higher polarity than that of DBT or DMDBT interact stronger with polar groups of the carbon surface $[22,23,27]$ and thus enhance the efficiency of the separation process.

Besides surface chemistry, porosity is also an important surface feature governing the performance of desulfurization adsorbents. Especially pores smaller than 7 or $10 \AA$ play a role since they are similar in their sizes to DBT and DMDBT molecules and thus enhance the adsorption potential $[10,12,18,22,25,26]$. Larger pores, even though they do not attract strongly the adsorbates via dispersive forces, also play a significant role in enhancing the 
capacity and selectivity when functional groups are located on their surface. This is owing to specific interactions of DBT and DMDBT with those groups [22, 23, 27]. The performance can be also increased when inorganic particles are deposited in such pores [16, 19, 24, 29].

Our recent studies demonstrated that sulfur heteroatoms in the carbon matrix enhance the performance of activated carbons as adsorbents of DBT and DMDBT from model diesel fuel $[27,28,30]$. Specifically thiophenic groups which can exists in small pores $[27,28,30]$ increase the adsorption capacity while selectivity is positively affected when sulfonic acid is present in larger pores. It contributes to the separation process imposing acid-base interactions with DBT and DMDBT and also to the oxidation of dibenzothiophenes in reactive adsorption [26-28]. Taking this into account, the objective of this study is to investigate the role of oxygen, sulfur and phosphorus species existing in a carbon matrix in the ultra deep desulfurization. Since the roles of oxygen and sulfur have been analyzed in detail elsewhere $[18,22,23,26-28]$ the main emphasis here is on the role of phosphorus. This heteroatom is usually bonded in the forms of phosphates. Its positive effects on catalysis and separation processes have been studied extensively by Puziy and coworkers $[31,32]$. In this study we use model diesel fuel with arenes and low sulfur content (20 ppmw). The carbons studied are those polymer based (containing sulfur) which were additionally activated using phosphoric acid and $\mathrm{CO}_{2}$. This led to the spectrum of textural and chemical properties. The results of surface characterization using various methods are analyzed in order to identify specific surface features affecting the performance of these carbons as desulfurization media. 


\section{Experimental}

\subsection{Materials}

Poly(4-styrenesulfonic acid-co-maleic acid) sodium salt was used as a nanoporous carbon precursor. The powdered polymer was carbonized at $500{ }^{\circ} \mathrm{C}$ (char) and $800{ }^{\circ} \mathrm{C}$ (carbon) for 40 min under nitrogen, in a horizontal furnace. The details on the initial sample preparation are described in Ref. [33]. The sample obtained at $800{ }^{\circ} \mathrm{C}$ is referred as $\mathrm{C} 1$. The char obtained at $500{ }^{\circ} \mathrm{C}$ was extensively washed in a Soxhlet apparatus to removed sodium and then heated at nitrogen at $800{ }^{\circ} \mathrm{C}$. It is referred to as $\mathrm{C} 2$. The $\mathrm{C} 1$ carbon or washed char obtained at $500{ }^{\circ} \mathrm{C}$ were mixed with the solution of phosphoric acid at a ratio 0.80 gram of $\mathrm{H}_{3} \mathrm{PO}_{4}$ /gram of carbon material, dried in air and then heated under nitrogen flow $\left(100 \mathrm{~mL} / \mathrm{min}, 10{ }^{\circ} \mathrm{C} / \mathrm{min}\right)$ at $800{ }^{\circ} \mathrm{C}$ for 40 min. The materials obtained are referred to as $\mathrm{C} 1 \mathrm{P}$ and $\mathrm{C} 2 \mathrm{P}$, respectively. To remove an excess of acid, the carbons were extensively washed in a Soxhlet apparatus to constant $\mathrm{pH}$ with periodic changes of water.

The subsamples of $\mathrm{C} 1$ and $\mathrm{C} 2 \mathrm{P}$ were activated in a flow of carbon dioxide $(50 \mathrm{~mL} / \mathrm{min})$ at $850{ }^{\circ} \mathrm{C}$ for 2 hours. The materials are referred to as $\mathrm{C} 1 \mathrm{~A}$ and $\mathrm{C} 2 \mathrm{PA}$, respectively.

The exhausted samples after adsorption of DBT and DMDBT are designed with letter S and those after heated at $300{ }^{\circ} \mathrm{C}$ to remove solvents and arenes in order to better analyze the mechanism of DBT and DMDBT interactions with the carbon surface with a letter $-\mathrm{H}$.

\subsection{Methods}

\subsubsection{Adsorption of DBT and 4,6-DMDBT}

In order to carry out the adsorption from liquid phase model diesel fuel (MDF) was prepared. Model fuel contained same molar concentrations of dibenzothiophene (DBT), 4,6- 
dimethyldibenzothiophene (DMDBT), naphthalene (Nap) and 1-methylnaphthalene (1-MNap) in mixture of decane and hexadecane (1:1). All compounds were obtained from Sigma-Aldrich Co. and used as received. Molar concentration of each compound in fuel was $2.35 \times 10^{-7} \mathrm{~mol} / \mathrm{mL}$. The corresponding total sulfur concentration was $20 \mathrm{ppmw}$.

Adsorption process was carried out in the dynamic conditions and at ambient temperature and pressure. Dry carbons (at $120{ }^{\circ} \mathrm{C}$ overnight) with granule sizes of $0.212-0.425 \mathrm{~mm}$ were packed into $60 \mathrm{~mm}$ polyethylene column with $4 \mathrm{~mm}$ inside diameter. The height of carbon bed was approximately $55 \mathrm{~mm}$ with volume of $0.70 \mathrm{~mL}$. Model fuel was passed into the column with adsorbent from the top by peristaltic pump (MasterFlex C/L) with a flow rate of $8.3 \mathrm{~mL} / \mathrm{h}$. Effluent was collected periodically in $5 \mathrm{~mL}$ fractions and the concentration of arenes and thiophenes was determined. Then based on the mass of the adsorbent, concentration, and the flow rate the breakthrough curves were constructed and the breakthrough capacities were calculated.

The concentration of arenes and thiophenes in effluent after adsorption of dibenzothiophene (DBT) and 4,6-dimethyldibenzothiophene (DMDBT) in the presence of naphthalene (Nap) and 1-methylnaphthalene (1-MNap) were determined by a Waters 2690 liquid chromatograph equipped with a Waters 996 photodiode array detector. The details of the method are described elsewhere [22]. The lowest limits of detection were $0.05 \mathrm{ppm}$ for DBT and DMDBT and 0.07 ppm for naphthalene and 1-methylnaphthalene.

The capacities were calculated at the breakthrough point when the measured concentration is first $>0$ (Bth), at $\mathrm{C} / \mathrm{Co}=0.7(0.7)$ and at saturation $(\mathrm{S})$. 


\subsubsection{Thermal Analysis}

Thermal gravimmetry (TG) curves were obtained using a TA Instruments thermal analyzer. The samples (initial or exhausted) were exposed to an increase in temperature of $10{ }^{\circ} \mathrm{C} / \mathrm{min}$ up to $1000{ }^{\circ} \mathrm{C}$ while the nitrogen flow rate was held constant at $100 \mathrm{~mL} / \mathrm{min}$.

\subsubsection{Characterization of Pore Structure of Adsorbents}

Nitrogen isotherms were measured at $-196{ }^{\circ} \mathrm{C}$ using an ASAP 2010 (Micromeritics). Prior to each measurement, all samples were outgassed at $120^{\circ} \mathrm{C}$ until the vacuum $10^{-5}$ Torr was reached. Approximately $0.20 \mathrm{~g}$ to $0.25 \mathrm{~g}$ of sample was used for these analyses. The surface area, $\mathrm{S}_{\mathrm{BET}}$ was calculated from BET method, whereas for the volume of pores smaller than $10 \AA, \mathrm{V}_{<10}$ $\AA$, surface in pores larger than $10 \AA, \mathrm{S}_{>10} \AA$, micropore volume, $\mathrm{V}_{\text {mic }}$, and mesopore volume, $\mathrm{V}_{\text {mes, }}$ the DFT approach was applied [34]. The total pore volume was calculated from the last point of the isotherm at relative pressure equal to 0.99 . Pore size distributions were determined using NLDFT [35]. Additionally, the volume of pores smaller than $7 \AA$ (narrow micropores) was assessed from $\mathrm{CO}_{2}$ adsorption isotherms at $0{ }^{\circ} \mathrm{C}$ (Tristar 3020 , Micromeritics) with the DR formulism and using $1.023 \mathrm{~g} / \mathrm{cm}^{3}$ as the density of adsorbed $\mathrm{CO}_{2}$ and 0.36 as the value of the $\beta$ parameter.

\subsubsection{Elemental analysis}

The content of sulfur was measured using Perkin Elmer total sulfur analyzer. The content of phosphorus was determined using ICP method. 


\subsubsection{Surface $p H$}

A $0.1 \mathrm{~g}$ sample of dry carbon powder was added to $5 \mathrm{ml}$ of distilled water and the suspension was stirred overnight to reach equilibrium. Then the $\mathrm{pH}$ of suspension was measured.

\subsubsection{XPS}

XPS spectra were obtained on a SCIENTA 200 X-ray photoelectron spectrometer equipped with a conventional hemispherical analyzer. The latter was operated at constant pass energy of $100 \mathrm{eV}$ in the fixed transmission mode. The incident radiation used was a monochromatic $\mathrm{Al} \mathrm{K \alpha}(1486$, $6 \mathrm{eV})$ operated at $420 \mathrm{~W}(14 \mathrm{kV} ; 30 \mathrm{~mA})$. Analysis was performed using a takeoff angle of $90^{\circ}$, and the base pressure in the analysis chamber was $\sim 10-9$ mbar. The analyzed surface area was $\sim$ $3 \mathrm{~mm}^{2}$. The spectrometer energy scale was calibrated to the $\mathrm{Ag} 3 \mathrm{~d} 5 / 2, \mathrm{Au} 4 \mathrm{f} 7 / 2$, and $\mathrm{Cu} 2 \mathrm{p} 3 / 2$ core level peaks set, respectively, at a binding energy of 368.2, 84.0, and $932.7 \mathrm{eV}$. All binding energies are referenced to the adventitious $\mathrm{C} 1 \mathrm{~s}$ peak at $285.0 \mathrm{eV}$. The survey and multiregions spectra were recorded for $\mathrm{C} 1 \mathrm{~s}, \mathrm{O} 1 \mathrm{~s}, \mathrm{~S} 2 \mathrm{p}$ and $\mathrm{P} 2 \mathrm{p}$ photoelectron peaks. CasaXPS software was used for data treatment using a Shirley background correction. The models used to decompose the C1s, S2p and P2p peaks were those proposed by Desimoni et al. [36], Terzyk [37] and Puziy et al. [38], respectively. The O1s region was decomposed, as suggested by Zhou et al.[39]; in addition, two components corresponding to $\mathrm{P}-\mathrm{O}$ and $\mathrm{P}=\mathrm{O}$ contributions were used.

\subsubsection{Potentiometric titration}

Potentiometric titration measurements were performed with a DMS Titrino 716 automatic titrator (Metrohm). Volumetric standard $\mathrm{NaOH}(0.1 \mathrm{M})$ was used as the titrant. The experiments were 
done in the $\mathrm{pH}$ range of 3-10. The details of the experimental procedure are described elsewhere [22].

The experimental data was transformed into a proton binding isotherm, Q, representing the total amount of protonated sites, which is related to the $\mathrm{pK}_{\mathrm{a}}$ distribution by the integral equation [40]. The solution of this equation is obtained using the numerical procedure [40, 41], which applies regularization combined with non-negativity constraints.

\section{Results and Discussion}

The breakthrough curves for all components of MDF are presented in Figure 1. The comparison of the calculated capacities is shown in Figure 2. Even though the breakthrough curves for C1 were published previously [22], the results obtained on this carbon are included in this paper for the clarity of data interpretation. The breakthrough curves for $\mathrm{C} 2$ are not shown because of the poor performance of this material. The curves show that all carbons behave similarly when the adsorption of arenes is considered. The adsorption of DBT and DMDBT causes the displacement of arenes from the pore system, which is demonstrated in $\mathrm{C} / \mathrm{Co}$ values $>1$. For all carbons but $\mathrm{C} 2$ and C2P DMDBT is preferably adsorbed in comparison with DBT. This suggests the presence of surface features in these two carbons, which favor DBT retention. Dibenzothiophene is a slightly smaller molecule than 4,6-dimethyldibenzothiophene $(5.54 \AA$ compared to $5.54 \AA[42]$ ) and it is more polar (dipole moment of DBT and DMDBT are 1.362 D and $0.748 \mathrm{D}$, respectively) [7] and less basic [43]. Treatment with phosphoric acid increases the capacity up to about $30 \%$ and the effect is especially seen at the breakthrough point. Activation with $\mathrm{CO}_{2}$ has mixed effects on the performance. Even the main purpose of this treatment was to 
increase porosity, the high volume of pores larger than $10 \AA$ can have a detrimental effect on the performance owing to a decrease in adsorption potential in such pores [44].

The changes in the parameters of the porous structure (calculated from adsorption of nitrogen and carbon dioxide) upon the treatment applied are listed in Table 1. Interestingly, even though the final temperatures of treatment for $\mathrm{C} 1$ and $\mathrm{C} 2$ are the same, two-steps-carbonization results in the carbon with 3 times smaller porosity than that for $\mathrm{C} 1$. This is owing to the removal of sodium which was indicated as one of the pore former in this kind of carbons [33]. Treatment with phosphoric acid increases the porosity in visible ways, however, no dramatic changes are revealed. On the other hand, $\mathrm{CO}_{2}$ activation significantly increases porosity especially in the range of large micropores. Very small micropores, $<10 \AA$, are not affected dramatically. In fact for all carbons but $\mathrm{C} 2$ the volume of pores smaller than $7 \AA, \mathrm{V}_{\mathrm{CO} 2}$, is quite similar. Similarity in the volume of small micropores is seen on pore size distributions presented in Figure 3. Here C2 and $\mathrm{C} 2 \mathrm{P}$ stand out as very homogeneous carbons in the range of micropores with almost all pores smaller than $10 \AA$. This can explain their higher affinity to retain DBT and DMDBT. One has to remember that $10 \AA$ is the pore size seen by nitrogen molecule with the size of $1.62 \AA$ [45]. Activation increases significantly the volume in pores with sizes between 10-30 A. Even though those pores are up to 5 times larger than the adsorbate molecules they still can significantly contribute to the removal process if bulky functional groups are present on their walls. These groups decrease the apparent size of the pore for bulky DBT and DMDBT molecules and introduce specific polar or acid -base interactions. The high volumes of pores with sizes between 10-30 $\AA$ in C2PA can be responsible for the high adsorption capacity for both DBT and DMDBT on this carbon. 
To evaluate the influence of the above-mentioned factors the surface chemistry was analyzed using the spectroscopic and wet titration approaches. The proton binding curves used to calculate the pKa distributions show that the treatment of our carbons with phosphoric acid increases the acidity as opposed to activation with $\mathrm{CO}_{2}$. The amount of relatively strongly acidic $\left(\mathrm{pK}_{\mathrm{a}}<8\right)$ and weakly acidic $\left(\mathrm{pK}_{\mathrm{a}}>8\right)$ groups are listed in Table 2 . Interestingly, for all carbons the ratio of these groups are close to $1: 1$, with the exception of $\mathrm{C} 2 \mathrm{P}$ which has twice fewer groups with $\mathrm{pK}_{\mathrm{a}}$ $<8$ than those with higher $\mathrm{pK}_{\mathrm{a}}$. Even though the ratio of the acidic to basic groups are rather similar, there are obvious differences in their number and strength. The most acidic samples are $\mathrm{C} 2 \mathrm{P}$ and $\mathrm{C} 2 \mathrm{PA}$, which also have lowest surface $\mathrm{pH}$ values, and the most basic are $\mathrm{C} 2$ and $\mathrm{C} 1 \mathrm{~A}$. The latter sample is basic in spite of the high number of groups detected on the surface. Apparently activation with $\mathrm{CO}_{2}$, besides formation of porosity, decreases the amount of strongly acidic groups. This is due to the decomposition of the varied surface functional groups of the carbons during the activation at high temperature (i.e, $850{ }^{\circ} \mathrm{C}$ ). The acidity of the carbons can be due to the presence of sulfur, oxygen or phosphorus-containing functional groups. Strongly acidic sulfonic can be removed during activation at high temperatures [46]. Similarly carboxylic groups can be also removed and replaced by quinone or pyrone type oxygen [47]. Moreover, if acidity is related to the presence of phosphorus in the form of phosphate/pyrophosphates that phosphorus can get reduced by carbon during activation leading to the formation of less acidic metaphosphate groups [48].

The rearrangements of the surface heteroatoms mentioned above were studied using XPS methods. The contents of heteroatoms on the surface from XPS data and elemental analysis are 
listed in Table 2. Discrepancies between the quantities determined by both techniques are due to the fact that XPS analyzes the surface of the materials (5-10 nm layer thickness) whereas the elemental analysis data refers to the bulk material.

Interestingly, there is three times more sulfur on the surface of $\mathrm{C} 2$ than on that of $\mathrm{C} 1$. Two stepcarbonization must stabilize sulfur atoms on the surface of the former sample, whereas for the latter that sulfur was likely used as a pore former when released from a hot carbon matrix between 500 and $800{ }^{\circ} \mathrm{C}$ [33]. Phosphoric acid activation of char obtained at $500{ }^{\circ} \mathrm{C}$ increased the oxygen content, especially in the $\mathrm{C} 2 \mathrm{P}$ sample. While the sulfur content is similar to those in their corresponding pristine samples, a significant increase in the phosphorus content was found, especially for C2P. Since in this case, a char (not fully carbonized material) was exposed to phosphoric acid, the low degree of carbonization could be responsible for its higher reactivity with phosphorus atoms. Although XPS data revealed similar phosphorus content after $\mathrm{CO}_{2}$ activation (samples $\mathrm{C} 2 \mathrm{P}$ and $\mathrm{C} 2 \mathrm{PA}$ ), the increase in the value obtained by elemental analysis indicates that some phosphorus has moved from the surface to the bulk of the sample. The activation also significantly reduced the oxygen content, for both series of samples. Even though the overall amount of functional groups on the surface did not change significantly after $\mathrm{CO}_{2}$ activation, they are apparently less acidic and thus in a more reduced form.

The results of the deconvolution of O1s, S2p and P2p spectra allowed the identification of the different functionalities created on these materials upon the different thermal treatments. The XPS results as atomic concentration of the different oxygen, sulfur and phosphorus species are presented in Table 3. Figure 4 show the examples of the deconvolution results for C2P sample. 
Data has been calculated by multiplying the relative abundance of each group by the total atomic content of the corresponding heteroatom.

In the case of oxygen the $\mathrm{O} 1, \mathrm{O} 2, \mathrm{O} 3$ and $\mathrm{O} 4$ peaks represent $\mathrm{C}=\mathrm{O}$ in ketones, $\mathrm{C}=\mathrm{O}$ in carboxylic groups, anhydrides and lactones, $\mathrm{C}-\mathrm{O}-\mathrm{C}$ in ether groups and $\mathrm{C}-\mathrm{OH}$ in hydroxyl (phenol) groups, carboxylic acids, anhydrides and lactones, respectively; corresponding binding energies are $529.5 \mathrm{eV}, 530.1 \mathrm{eV}, 531 \mathrm{eV}$ and $531.7 \mathrm{eV}$. Taking into account the presence of sulfur and phosphorus in theses samples, and the strong signal obtained for the O1s line, it was possible to separate the contribution of phosphorus and sulfur components. Bands corresponding to oxygen linked to both elements have been identified at $529.9 \mathrm{eV}, 530.9 \mathrm{eV}$ and $532.6 \mathrm{eV}$ for $\mathrm{S}-\mathrm{O}, \mathrm{O}=\mathrm{P}$ and $\mathrm{O}-\mathrm{P}$ groups, respectively. The deconvolution of the $\mathrm{P} 2 \mathrm{p}$ peak was assigned to three major components: phosphates and pyrophosphates-like structures $(\mathrm{P} 1$ at $132.5 \mathrm{eV})$, metaphosphates (P2 at $134.3 \mathrm{eV})$ and phosphorus pentoxide (P3 at $135.6 \mathrm{eV})$. Analogously, in the case of sulfur, the S1, S2, S3, S4 and S5 peaks represent R-SH in thiophenic groups, C-S-C/ $\mathrm{R}-\mathrm{S}_{2}-\mathrm{OR}$ in sulfides and thioethers, $\mathrm{R}_{2}-\mathrm{S}=\mathrm{O}$ in sulfoxides, $\mathrm{R}-\mathrm{SO}_{2}-\mathrm{R}$ in sulphones and $\mathrm{R}-\mathrm{SO}_{3} \mathrm{H}$ in sulfonic acids, respectively. Their corresponding binding energies are: $163.5 \mathrm{eV}, 164.5 \mathrm{eV}, 167$ $\mathrm{eV}, 168 \mathrm{eV}$ and $169.7 \mathrm{eV}$.

The results show that the two step carbonization resulted in a more complex surface chemistry. The oxygen groups are predominant in the $\mathrm{C} 1$ sample, mainly in the form of ethers and carboxylic functionalities. The amount of carboxylic acids decreased in the $\mathrm{C} 2$ carbon, which also presents a variety of sulfur groups, mainly in the form of thiols and thioethers. Sulfur is also incorporated as sulfoxides and sulfonic acids in lower quantities. This confirms that, as suggested above, the two-step carbonization of polymer "stabilized" sulfur in the more reduced 
and thus more thermally stable forms. The larger amount of carboxylic and sulfonic acids in $\mathrm{C} 1$ compared to C2 explains the higher initial acidity of the former (Table 2).

Despite the rich surface chemistry and higher amount of sulfur incorporated to the carbon matrix of sample C2 compared to $\mathrm{C} 1$, the latter retains higher amounts of DBT and DMDBT (Figure 2). The differences are very large in the breakthrough points (where high energy sites are involved) and become slightly lower at the saturation point. This behavior can be attributed to two factors: the lower textural development (Table 2) and basic $\mathrm{pH}$ of sample $\mathrm{C} 2$ compared to $\mathrm{C} 1$. As mentioned above, the two-step carbonization fixes a larger amount of sulfur in the carbon matrix; thus, even if the sulfur-sulfur specific interactions would be favored in $\mathrm{C} 2$ by the sulfur groups, the contribution of physisorption to the overall amount adsorbed is much lower than in $\mathrm{C} 1$ due to the low pore volume. Consequently the overall capacity decreases.

The treatment with phosphoric acid incorporated phosphorus mainly in phosphates/pyrophosphates ( $\mathrm{P} 1$, over $80 \%$ of all phosphorus) in both samples, along with small quantities of metaphosphates (P2) and phosphorus pentoxide (P3). The ratio P1:P2 is higher for C2P compared to C1P; since metaphosphate groups are less acidic [48], this along with the lower amount of carboxylic acids accounts for the higher acidity of $\mathrm{C} 2 \mathrm{P}$ over $\mathrm{C} 1 \mathrm{P}$.

While $\mathrm{P} 1$ and $\mathrm{P} 2$ can be incorporated to the carbon matrix, $\mathrm{P}_{2} \mathrm{O}_{5}$ should exist as small particles distributed on the surface. An important difference is that the ratio of double over single P-O bond increased after the two step carbonization (sample C2P). This confirms the abovementioned higher reactivity of the char during the phosphoric acid activation, which does not 
only promote a carbon matrix of a rich surface chemistry (higher $\mathrm{S}$ and $\mathrm{P}$ contents) but it also favors the oxidation of the phosphorus present on the carbon surface. For the C2P sample, the phosphoric acid activation also resulted in a slight oxidation of sulfur shown by the increase in sulfoxides and sulfones. These are labile groups which decomposed upon activation at higher temperatures (C2PA sample).

The $\mathrm{CO}_{2}$ activation decreases the amount of the labile groups such as sulfoxides, sulfones and particularly carboxylic groups, due to the high temperature of this treatment. The decomposition of carboxylic groups explains the increase in the samples $\mathrm{pH}$ observed for $\mathrm{C} 1 \mathrm{~A}$, as abovementioned. This was not the case for $\mathrm{C} 2 \mathrm{P}$, which still displayed an acidic character after the $\mathrm{CO}_{2}$ activation despite the decrease in the amount of oxygen in carboxylic groups. Since the nature of abundance of P-groups was not modified after activation with $\mathrm{CO}_{2}$, the high acidity of $\mathrm{C} 2 \mathrm{PA}$ should be linked mainly to the phosphorus compounds. In fact, all three phosphorus compounds should result in Bronsted acidity when the samples are immersed in water. Such acidic centers should also exist when carbons are in equilibrium with ambient, containing humidity, air.

Since phosphates, pyrophosphates and metaphosphates are rather bulky species, we do not expect them to exist in very small pores less than $10 \AA$ their diameter. The same restrictions should apply to $\mathrm{P}_{2} \mathrm{O}_{5}$ particles. On the other hand, the existence of these phosphorus species in larger pores (10-30 $\AA$ ) should be very beneficial for DBT and DMDBT adsorption. Those pores can be still "seen" by nitrogen molecules as quite large but their effective size for DBT and DMDBT adsorption is likely much smaller, which enhances the adsorption potential. This can explain the highest adsorption capacity, even at breakthrough found for $\mathrm{C} 2 \mathrm{PA}$. This carbon has a 
very high volume of pores $10-20 \AA$, high content of phosphorous, low $\mathrm{pH}$ and also relatively high content of sulfur in the reduced form (Table 3).

As indicated previously, that sulfur especially thiophenic, can exist in pores smaller than $10 \AA$ and results in DBT and DMDBT adsorption via sulfur-sulfur specific interactions. Therefore both sulfur and phosphorous groups contribute to the enhanced capacity found on the C2PA carbon. Since phosphorus groups likely do not exist without bonds with oxygen [48], that oxygen, owing to its polarity and contribution to specific interactions does not remain without any influence on the amount adsorbed.

In order to analyze the effect of phosphorus, the dependence of the adsorption capacity on the total content of phosphorus and each species (P1, P2 and P3) was analyzed. As a general trend, the amount of DBT and DMDBT adsorbed increases with the phosphorus content. This is much more evident for the sample prepared by a two-step carbonization (C2P vs $\mathrm{C} 2)$; although there is an increase in the porous features after phosphoric activation, this marked large increase in the adsorption capacity could be attributed to the acidity of the sample given by the phosphate groups. Such an effect of phosphate groups was also proposed by Wang and coworkers as responsible for an increased DBT adsorption capacity measured at equilibrium conditions [49]. However, the dependence of the uptake on the phosphorus content does not follow a linear trend. These results represent the complexity of the adsorption process where the physical adsorption in very small pores and specific adsorption in small and larger pores coexist. Their contribution changes with the progress of adsorption when less and less energetic sites are occupied. Moreover, heteroatoms and acidic groups of different strength contribute to this complexity. It 
has to be mentioned here that the total sulfur removal capacities measured on C2PA at dynamic conditions from low sulfur concentration fuel are high and reach $0.32 \mathrm{mmol}-\mathrm{S} / \mathrm{g}$ and $0.49 \mathrm{mmol}$ S/g at breakthrough and saturation, respectively. So far, in our research effort the highest capacities of total sulfur adsorbed at the breakthrough point of 0.35 and $0.37 \mathrm{mmol}-\mathrm{S} / \mathrm{g}$ of adsorbent were measured on sulfur and nitrogen-enriched polymer-based carbon, respectively $[28,50]$. The highest capacities reported by other research groups are $0.36 \mathrm{mmol}-\mathrm{S} / \mathrm{g}$ of adsorbent on oxidized micro and micro/mesoporous activated carbons (from diesel fuel containing $400 \mathrm{ppmw}$ of sulfur [51]. The total sulfur adsorption capacity on activated carbon without any modification (Nuchar SA) was reported to be $0.49 \mathrm{mmol}-\mathrm{S} / \mathrm{g}$ of adsorbent with 687 ppmw sulfur in fuel [7]. Eve though Wang and coworkers reported about $0.9 \mathrm{mmol}-\mathrm{S} / \mathrm{g}$ on their phosphoric activated carbons those capacities were measured at equilibrium conditions from the fuel containing $300 \mathrm{ppm}$ of DBT [49]. Ania and Bandosz reported $3.6 \mathrm{mmol}-\mathrm{S} / \mathrm{g}$ measured at equilibrium on copper containing carbons [16]. One has to take into account that values have been obtained at different initial concentration of sulfur, for which direct comparison is rather inappropriate (typically, the higher solution concentration, the higher adsorption capacity).

Besides the adsorption capacity, the selectivity to remove DBT and DMDBT with reference to arenes (naphthalene in our case) present in the diesel fuel is an important parameter to consider. The selectivities obtained on our materials are presented in Figure 5. As it can be seen, the highest values were obtained at the breakthrough points where the most energetic sites are involved in adsorption and where the adsorption forces are the strongest. The carbons with phosphorus have higher selectivities than their corresponding counterparts, especially for DBT removal. At $\mathrm{C} / \mathrm{Co}=0.7$ and saturation $(\mathrm{S})$ the selectivities to remove $\mathrm{DBT}$ are even greater than those for DMDBT. This clearly indicates that there are the specific features on the surface of 
these materials which favor DBT adsorption. Even though DBT is less basic than DMDBT [43] the preferential adsorption of the former on the carbon surface can be explained by its smaller and more compact size, and thus more favored accessibility to occupy high-energy centers when bulky phosphates are present on the surface. Undoubtedly, the chemical character of the adsorbate plays a role but the attraction/accommodation of the molecule and pore filling are also important aspects of the adsorption mechanism.

As for the role of the phosphorus functionalities, higher selectivities towards DBT are obtained for $\mathrm{C} 2 \mathrm{P}$ and $\mathrm{C} 2 \mathrm{PA}$ (compared to $\mathrm{C} 1 \mathrm{P}$ ), which presented large amounts of $\mathrm{P} 1$ and $\mathrm{P} 3$ groups, of more acidic character than metaphosphates. This trend does not seem to apply for DMDBT, where $\mathrm{C} 1 \mathrm{P}$ shows higher selectivity values than $\mathrm{C} 2 \mathrm{P}$. This shows once again the complexity of the desulfurization process.

No further dependence was found concerning other group/heteroatoms, even though different approaches were undertaken (i.e., the percentage of each group in the total content of heteroatoms entities, the absolute amount of these species normalized per surface area in pores larger than $20 \AA$ (referred elsewhere as a specific functional group index [50]). Once again these results reflect the complexity of the desulfurization process on our materials.

The highest selectivities calculated in reference to naphthalene [7] found in our previous research efforts were 5.2 and 5.6 for DBT and DMDBT [28] and 6.6 and 5.4 for DBT and DMDBT [27] on sulfur enriched polymer based carbon modified with $\mathrm{H}_{2} \mathrm{~S}$ and nanoporous carbon with sulfur and oxygen functionalities, respectively. The selectivities reported in the literature are 3.0 and 
4.5 for DBT and DMDBT for the micro/mesoporous carbon [7] and 3.9 and 4.9 for DBT and DMDBT on microporous activated carbon [51].

On the other hand, the presence of phosphorus in the carbon matrix seems to have a marked effect on the reactive adsorption mechanisms. The DTG curves of the exhausted samples (labeled as S) presented in Figure 6 show differences in the chemistries of species deposited on the surface. The exhausted samples were also heated at $300{ }^{\circ} \mathrm{C}$ (labeled as $\mathrm{H}$ ) in order to remove the solvents (boiling points of hexadecane and decane are 287 and $174{ }^{\circ} \mathrm{C}$, respectively [52]) as well as the adsorbed arenes (boiling points of naphthalene and 1-methylnaphthalene are $240{ }^{\circ} \mathrm{C}$ and $218{ }^{\circ} \mathrm{C}$, respectively [52]). Taking into account the boiling points for DBT and DMDBT (332 and $340-350{ }^{\circ} \mathrm{C}$, respectively $[52,53]$ ) as well as the breakthrough curves and the high selectivities obtained for both compounds, we can assume that the strongest adsorption centers, those located in small pores, are rather occupied by the DBT and DMDBT molecules. Moreover, it has to be mentioned that the desorption of a given compound can shift to slightly higher temperatures when the molecules are located in the pores similar to their sizes.

The DTG curves for the exhausted $\mathrm{C} 1, \mathrm{C} 1 \mathrm{~A}$ and $\mathrm{C} 2$ curves resemble those reported previously for other carbons $[22,33]$. Two peaks with maxima at about 350 and $480{ }^{\circ} \mathrm{C}$ were assigned to the removal of DBT and DMDBT (first peak) and their oxidation products (sulfoxides and sulfones), which have higher boiling points than their parent compounds [54]. The oxidation of DBT and DMDBT on the modified carbon was suggested as one of the route of reactive adsorption leading to efficient desulfurization $[22,23,27,28,51]$. As a result of the increasing polarity of the compounds to be removed, their removal selectivity increases when polar groups containing 
oxygen or sulfur are present on the surface. Interestingly, after the heating treatment to remove solvents and arenes (series $\mathrm{H}$ ) of the exhausted samples containing phosphorus in the temperature range between $300-500{ }^{\circ} \mathrm{C}$ only one broad peak centered at about $400{ }^{\circ} \mathrm{C}$ is revealed. We assign it to the removal of DBT (a slight broadening towards lower temperatures) and DMDBT.

The lack of reactive adsorption on the modified samples is linked to the low content of oxygen and the presence of phosphorus. In fact the latter must be the most important surface feature governing the adsorption mechanism. Since phosphorus is known as an oxidation suppressant for carbonaceous materials [55-57], we link the observed phenomena to its effect on suppressing oxidation of DBT and DMDBT on the surface of modified carbons. Following the analysis of the phosphorus effects discussed in the literature [56, 57] it is plausible to assume that phosphorous species act as physical barriers against the close contact of DBT and DMDBT with chemisorbed oxygen. Moreover, the theoretical calculations by Kuts and coworkers [58] indicated good electron-donor properties of phosphorus incorporated to the carbon matrix in specific "pyrrole- like clusters" and therefore they likely contribute to observe suppressed oxidation reactions on our carbons. The inhibiting role of phosphorus in combustion of isobutane on activated carbons has been investigated by Schwartz and coworkers [59]. They linked this effect mainly to the interference of phosphorus with active sites availability.

\section{Conclusions}

The results presented in this paper show the positive effect of phosphorus incorporated to the carbon matrix on the removal of DBT and DMDBT from model diesel fuel. When bulky 
orthophosphates, metaphosphates and $\mathrm{P}_{2} \mathrm{O}_{5}$ are present in the pores in the range of large micropores and small mesopores they decrease the effective pore diameters and thus make them more suitable to retain large DBT and DMDBT molecules. Moreover, these phosphorus species have a strong acidity and results in enhanced attraction of slightly basic dibenzothiophenes. The molecules are strongly and selectively adsorbed on the surface even though the oxidation does not take place. It is suppressed by the presence of phosphorus species. The performance is also enhanced by sulfur species in thiophenic compounds, which can be incorporated to the walls of small pores with sizes less than $10 \AA$. Such pores are the main centers for DBT and DMDBT adsorption via dispersive forces. The mentioned above effects of phosphorus in the capacity and selectivity and the oxidation suppressing effect make the carbons containing phosphorus attractive candidates for regeneration using heat treatment. Such materials are supposed to be thermally stable and the lack of reactive adsorption eliminates the concern on the decomposition of active, oxygen providing centers. This is the topic of our ongoing study.

\section{Acknowledgements}

This work was partially supported by PSC CUNY grant \# 62615-0040 and the NSF grant \# CBET-0930858. The authors are grateful to Mr. Albert V. Tamashausky of Asbury Carbon for his help with sulfur and phosphorus analysis and to Dr. Jacek Jagiello for the SAIEUS software. The help of Ph. Fioux with the XPS analysis is also acknowledged. 


\section{References}

1. Zhu W, Li H, Jiang X, Yan Y, Lu J, Xia J. Oxidative desulfurization of fuel catalyzed by peroxytungsten and peroxymolybdenum complexes in ionic liquids. Energy \& Fuels 2007;21:2514-6.

2. Cortes-Jacome MA, Morales M, Chavez CA, Ramirez-Verduzco LF, Lopez-Salinas E, Toledo-Antonio JA. $\mathrm{WOx} / \mathrm{TiO}_{2}$ catalysts via titania nanotubes for the oxidation of dibenzothiophene. Chem Mater 2007;19:6605-14.

3. Tao H, Nakazato T, Sato S. Energy-efficient ultra-deep desulfurization of kerosene based on selective photooxidation and adsorption. Fuel 2009;88:1961-9.

4. Matsuzawa S, Tanaka J, Sato S, Ibusuki T. Photocatalytic oxidation of dibenzothiophenes in acetonitrile using $\mathrm{TiO}_{2}$ : effect of hydrogen peroxide and ultrasound irradiation. $\mathrm{J}$ Photochem Photobio A: Chem 2002;149:183-9.

5. Gislason J. Phillips sulfur-removal process nears commercialization. Oil Gas J 2001;99:72-6.

6. Song C. An overview of new approaches to deep desulfurization for ultra-clean gasoline, diesel fuel and jet fuel. Catal Today 2003;86:211-63.

7. Kim JH, Ma X, Zhu A, Song C. Ultra-deep desulfurization and denitrogenation of diesel fuel by selective adsorption over three different adsorbents: A study on adsorptive selectivity and mechanism. Catal Today 2006;111:74-83.

8. Srivastav A, Srivastava VC. Adsorptive desulfurization by activated alumina. J Hazard Mater 2009;170:1133-40. 
9. Yang RT, Hernández-Maldonado AJ, Yang FH. Desulfurization of transportation fuels with zeolites under ambient conditions. Science 2003;301:79-81.

10. Alhamed YA, Bamufleh HS. Sulfur removal from model diesel fuel using granular activated carbon from dates' stones activated by $\mathrm{ZnCl}_{2}$. Fuel 2009;88:87-94.

11. Kumagai S, Ishizawa H, Toida Y. Influence of solvent type on dibenzothiophene adsorption onto activated carbon fiber and granular coconut-shell activated carbon. Fuel 2010;89:365-71

12. Wang Q, Liang X, Qiao W, Liu C, Liu X, Zhan L, Ling L. Preparation of polystyrenebased activated carbon spheres with high surface area and their adsorption to dibenzothiophene. Fuel Proces Technol 2009;90:381-7.

13. Jayne D, Zhang Y, Haji S, Erkey C. Dynamics of removal of organosulfur compounds from diesel by adsorption on carbon aerogels for fuel cell applications. Int J Hydrogen Energy 2005;30:1287-93.

14. Salem ABSH, Hamid HS. Removal of sulfur compounds from naphtha solutions using solid adsorbents. Chem Eng Technol 1997;20:342-7.

15. Jiang Z, Liu Y, Sun X, Tian F, Sun F, Liang C, You W, Han C, Li C. Activated carbons chemically modified by concentrated $\mathrm{H}_{2} \mathrm{SO}_{4}$ for the adsorption of the pollutants from wastewater and the dibenzothiophene from fuel oils. Langmuir 2003;19:731-6.

16. Ania CO, Bandosz TJ. Metal-loaded polystyrene-based activated carbons as dibenzothiophene removal media via reactive adsorption. Carbon 2006;44:2404-12.

17. Zou A, Ma X, Song C. Liquid-phase adsorption of multi-ring thiophenic sulfur compounds on carbon materials with different surface properties. J Phys Chem B 2006;110:4699-707. 
18. Ania CO, Bandosz TJ. Importance of structural and chemical heterogeneity of activated carbon surfaces for adsorption of dibenzothiophene. Langmuir 2005;21:7752-9.

19. Seredych M, Bandosz TJ. Template-derived mesoporous carbons with highly dispersed transition metals as media for the reactive adsorption of dibenzothiophene. Langmuir 2007;23:6033-41.

20. Yu G, Lu S, Chen H, Zhu Z. Diesel fuel desulfurization with hydrogen peroxide promoted by formic acid and catalyzed by activated carbon. Carbon 2005;43:2285-94.

21. Yang $\mathrm{Y}, \mathrm{Ku} \mathrm{H}$, Ying $\mathrm{P}$, Jiang $\mathrm{Z}$, Li C. Selective dibenzothiophene adsorption on modified activated carbons. Carbon 2007;45:3042-59.

22. Seredych M, Lison J, Jans U, Bandosz TJ. Textural and chemical factors affecting adsorption capacity of activated carbon in highly efficient desulfurization of diesel fuel. Carbon 2009;47:2491-500.

23. Deliyanni E, Seredych M, Bandosz TJ. Interactions of 4,6-dimethyldibenzothiophene with the surface of activated carbons. Langmuir 2009;25:9302-12.

24. Seredych M, Bandosz TJ. Adsorption of dibenzothiophenes on activated carbons with copper and iron deposited on their surfaces. Fuel Proces Technol 2010;91:693-701.

25. Jeon HJ, Ko CH, Kim SH, Kim JN. Removal of refractory sulfur compounds in diesel using activated carbon with controlled porosity. Energy \& Fuels 2009;23:2537-43.

26. Seredych M, Bandosz TJ. Adsorption of dibenzothiophenes on nanoporous carbons: Identification of specific adsorption sites governing capacity and selectivity. Energy \& Fuels 2010;24:3352-60. 
27. Seredych M, Bandosz TJ. Investigation of the enhancing effects of sulfur and/or oxygen functional groups of nanoporous carbons on adsorption dibenzothiophenes. Carbon 2011;49:1216-24.

28. Seredych M, Khine M, Bandosz TJ. Enhancement in dibenzothiophene reactive adsorption from liquid fuel via incorporation of sulfur heteroatoms into the nanoporous carbon matrix. ChemSusChem 2011;4:139-47.

29. Seredych M, Bandosz TJ. Selective adsorption of dibenzothiophenes on activated carbons with Ag, Co, and Ni species deposited on their surfaces. Energy \& Fuels 2009;23:373744.

30. Seredych M, Bandosz TJ. Removal of dibenzothiophenes from model diesel fuel on sulfur rich activated carbons. Appl Catal B: Environ, Submitted.

31. Puziy AM, Poddubnaya OI, Kochkin YuN, Vlasenko NV, Tsyba MM. Acid properties of phosphoric acid activated carbons and their catalytic behavior in ethyltert-butyl ether synthesis. Carbon 2010;48:706-13.

32. Puziy AM, Poddubnaya OI, Gawdzik B, Sobiesiak M, Tsyba MM. Phosphoric acid activation - functionalization and porosity modification. Appl Surf Sci 2007;253:573640.

33. Hines D, Bagreev A, Bandosz TJ. Surface properties of porous carbon obtained from polystyrene sulfonic acid-based organic salts. Langmuir 2004;20:3388-97.

34. Lastoskie C, Gubbins KE, Quirke N. Pore size distribution analysis of microporous carbons: a density functional theory approach. J Phys Chem B 1993;97:4786-96. 
35. Jagiello J, Olivier JP. A simple two-dimensional NLDFT model of gas adsorption in finite carbon pores. Application to pore structure analysis. J Phys Chem C 2009;113:19382-5.

36. Desimoni E, Casella GI, Salvi AM. XPS/XAES study of carbon fibres during thermal annealing under UHV conditions. Carbon 1992;30:521-6.

37. Terzyk AP. The influence of activated carbon surface chemical composition on the adsorption of acetaminophen (paracetamol) in vitro: Part II. TG, FTIR, and XPS analysis of carbons and the temperature dependence of adsorption kinetics at the neutral $\mathrm{pH}$. Colloids Surf A 2001;177:23-45.

38. Puziy AM, Poddubnaya OI, Socha RP, Gurgul J, Wisniewski M. XPS and NMR studies of phosphoric acid activated carbons. Carbon 2008;46:2113-23.

39. Zhou J-H, Sui Z-J, Zhu J, Li P, Chen D, Dai Y-C, Yuan W-K. Characterization of surface oxygen complexes on carbon nanofibers by TPD, XPS and FT-IR. Carbon 2007;45:785796.

40. Jagiello J. Stable numerical solution of the adsorption integral equation using splines. Langmuir 1994;10:2778-85.

41. Jagiello J, Bandosz TJ, Schwarz JA. Carbon surface characterization in terms of its acidity constant distribution. Carbon 1994;32:1026-8.

42. Cychosz KA, Wong-Foy AG, Matzger AJ. Liquid phase adsorption by microporous coordination polymers: removal of organosulfur compounds. J Am Chem Soc 2008; 130:6938-9.

43. Smith LO, Cristol SJ. Organic chemistry. New York: Reinhold; 1966. 
44. Everett DH, Powl JC. Adsorption in slit-like and cylindrical micropores in the Henry's Law region. J Chem Soc Faraday Trans 1976;72:619-36.

45. Gregg SJ, Sing KSW. Adsorption, surface area and porosity. New York: Academic Press; 1982.

46. Petit C, Kante K, Bandosz TJ. The role of sulfur-containing groups in ammonia retention on activated carbons. Carbon 2010;48:654-67.

47. Figueiredo JL, Pereira MFR, Freitas MMA, Órfão JJM. Modification of the surface chemistry of activated carbons. Carbon 1999;37:1379-89.

48. Bourbigot S, Le Bras M, Delobel R. Carbonization mechanisms resulting from intumescence - Part II. Association with an ethylene terpolymer and the ammonium polyphosphate-pentaerythritol fire retardant system. Carbon 1995;33:283-94.

49. Yu G-X, Sun J, Hou X-M, Zhou X-L, Li C-L, Chen L, Wang J-A. Adsorptive removal of dibenzothiophene in diesel fuel on an adsorbent from rice hull activated by phosphoric acid. Adv Mater Research 2010;132:133-140.

50. Seredych M, Hulicova-Jurcakova D, Bandosz TJ. Effect of the incorporation of nitrogen to a carbon matrix on the selectivity and capacity for adsorption of dibenzothiophenes from model diesel fuel. Langmuir 2010;26:227-33.

51. Zhou A, Ma X, Song C. Effects of oxidative modification of carbon surface on the adsorption of sulfur compounds in diesel fuel. Appl Catal B: Environ 2009;87:190-9.

52. Weast RC, Melvin JA. Handbook of chemistry and physics. $62^{\text {nd }}$ ed. Boca Raton FL: CRC Press; 1981: C-261-380.

53. Torrisi JS, Remans T, Swain J. The challenging chemistry of ultra-low-sulfur diesel. Process Technol Catalysis 2002;1-4. 
54. Babich IV, Moulijn JA. Science and technology of novel processes for deep desulfurization of oil refinery streams: a review. Fuel 2003;82:607-31.

55. Yue Z, Mangun CL, Economy J. Characterization of surface chemistry and pore structure of $\mathrm{H}_{3} \mathrm{PO}_{4}$-activated poly(vinyl alcohol) coated fiberglass. Carbon 2004;42:1973-82.

56. Wo X, Radovic LR. Inhibition of catalytic oxidation of carbon/carbon composites by phosphorus. Carbon 2006;44:141-51.

57. Wieber AP, Guzman JE, Wolf EE. An STM study of phosphoric acid inhibition of the oxidation of HOPG and carbon catalyzed by alkali salts. Caron 2006;44:2069-79.

58. Strelko VV, Kuts VS, Thrower, P.A. On the mechanism of possible influence of heteroatoms of nitrogen, boron and phosphorus in a carbon matrix on the catalytic activity of carbons in electron transfer reactions. Carbon 2000;38:1499-524.

59. Schwartz V, Xie H, Meyer III HM, Overbury SH, Liang C. Oxidative dehydrogenation of isobutene on phosphorus-modified graphitic mesoporous carbon. Carbon 2011;49:65968. 


\section{CAPTIONS TO THE FIGURES}

Figure 1.

The breakthrough curves for all components of MDF: A - C1A; B - C1P; C-C2P; D - C2PA.

Figure 2.

Comparison of the breakthrough capacities at breakthrough point (Bth), at $\mathrm{C} / \mathrm{Co}=0.7$ and at saturation (S) for DBT (A) and DMDBT (B).

Figure 3.

Pore size distributions for the materials studied.

Figure 4.

Example of XPS spectra of O1s, S2p and P2p for C2P carbon.

Figure 5.

Comparison of the selectivities of adsorption at breakthrough point (Bth), at $\mathrm{C} / \mathrm{Co}=0.7$ and at saturation (S) for DBT (A) and DMDBT (B).

Figure 6.

DTG curves in nitrogen for the exhausted samples and those heated at $300{ }^{\circ} \mathrm{C}$ after adsorption of DBT and DMDBT. 


\section{CAPTIONS TO THE TABLES}

Table 1.

Parameters of the pore structure calculated from $\mathrm{N}_{2}$ and $\mathrm{CO}_{2}$ adsorption isotherms.

Table 2 .

Elemental analysis results, surface content of atoms from XPS, pH values and the numbers of relatively strong and weak acidic groups $[\mathrm{mmol} / \mathrm{g}]$ determined from potentiometric titration experiments.

Table 3.

Surface concentration (atomic \%) of oxygen, sulfur and phosphorus species obtained by fitting the O1s, S2p and P2p core level peals of XPS spectra. 
Table 1. Parameters of the pore structure calculated from $\mathrm{N}_{2}$ and $\mathrm{CO}_{2}$ adsorption isotherms.

\begin{tabular}{|c|c|c|c|c|c|c|c|c|c|c|}
\hline Sample & $\begin{array}{c}\mathrm{S}_{\mathrm{BET}} \\
\left(\mathrm{m}^{2} / \mathrm{g}\right)\end{array}$ & $\begin{array}{l}\mathrm{S}_{>10 \AA} \\
\left(\mathrm{m}^{2} / \mathrm{g}\right)\end{array}$ & $\begin{array}{c}V_{t} \\
\left(\mathrm{~cm}^{3} / \mathrm{g}\right)\end{array}$ & $\begin{array}{c}V_{\text {meso }} \\
\left(\mathrm{cm}^{3} / \mathrm{g}\right)\end{array}$ & $\begin{array}{c}V_{<10} \AA \\
\left(\mathrm{cm}^{3} / \mathrm{g}\right)\end{array}$ & $\begin{array}{c}\mathrm{V}_{\text {mic }} \\
\left(\mathrm{cm}^{3} / \mathrm{g}\right)\end{array}$ & $\mathrm{V}_{\text {mic }} / \mathrm{V}_{\mathrm{t}}$ & $\begin{array}{c}\mathrm{V}_{\mathrm{CO} 2} \\
\left(\mathrm{~cm}^{3} / \mathrm{g}\right)\end{array}$ & $\begin{array}{c}\mathrm{L} \\
(\mathrm{nm}) \\
\end{array}$ & $\begin{array}{c}\mathrm{E}_{\mathrm{o}} \\
(\mathrm{kJ} / \mathrm{mol})\end{array}$ \\
\hline $\mathrm{C} 1$ & 1287 & 288 & 0.902 & 0.433 & 0.292 & 0.469 & 0.52 & --- & --- & --- \\
\hline $\mathrm{C} 1 \mathrm{~A}$ & 1644 & 470 & 1.214 & 0.647 & 0.284 & 0.567 & 0.47 & 0.328 & 0.75 & 25.81 \\
\hline $\mathrm{C} 1 \mathrm{P}$ & 1308 & 300 & 1.062 & 0.588 & 0.292 & 0.474 & 0.45 & 0.368 & 0.71 & 26.69 \\
\hline $\mathrm{C} 2$ & 453 & 21 & 0.377 & 0.210 & 0.157 & 0.167 & 0.44 & 0.250 & 0.55 & 30.89 \\
\hline $\mathrm{C} 2 \mathrm{P}$ & 684 & 62 & 0.497 & 0.232 & 0.226 & 0.265 & 0.53 & 0.304 & 0.62 & 28.83 \\
\hline $\mathrm{C} 2 \mathrm{PA}$ & 1854 & 662 & 1.275 & 0.675 & 0.218 & 0.600 & 0.47 & 0.301 & 0.81 & 24.71 \\
\hline
\end{tabular}


Table 2. Elemental analysis results, surface content of atoms from XPS, $\mathrm{pH}$ values and the numbers of relatively strong and weak acidic groups $[\mathrm{mmol} / \mathrm{g}]$ determined from potentiometric titration experiments.

\begin{tabular}{|c|c|c|c|c|c|c|c|c|c|}
\hline \multirow[t]{2}{*}{ Sample } & \multicolumn{2}{|c|}{$\begin{array}{l}\text { Elemental analysis } \\
\text { in wt. } \%\end{array}$} & \multicolumn{4}{|c|}{ XPS in at. $\%$} & \multirow[t]{2}{*}{$\mathrm{pH}$} & \multirow{2}{*}{$\mathrm{pK}_{\mathrm{a}}<8$} & \multirow[t]{2}{*}{$\mathrm{pK}_{\mathrm{a}}>8$} \\
\hline & $\mathrm{S}$ & $\mathrm{P}$ & $\mathrm{C}$ & $\mathrm{O}$ & $\bar{S}$ & $\bar{P}$ & & & \\
\hline $\mathrm{C} 1$ & 0.50 & --- & 92.3 & 7.4 & 0.3 & 0.0 & 4.70 & 0.377 & 0.311 \\
\hline $\mathrm{C} 1 \mathrm{~A}$ & 0.57 & --- & 94.4 & 4.9 & 0.7 & 0.0 & 7.41 & 0.301 & 0.399 \\
\hline C1P & 0.23 & 0.035 & 88.5 & 9.2 & 0.5 & 1.9 & 3.85 & 0.357 & 0.365 \\
\hline $\mathrm{C} 2$ & --- & --- & 94.2 & 3.6 & 2.2 & 0.0 & 7.63 & 0.256 & 0.324 \\
\hline $\mathrm{C} 2 \mathrm{P}$ & 3.07 & 0.10 & 83.1 & 11.2 & 2.2 & 3.4 & 2.90 & 0.708 & 0.372 \\
\hline $\mathrm{C} 2 \mathrm{PA}$ & 6.00 & 1.16 & 83.8 & 8.6 & 3.6 & 3.9 & 3.26 & 0.493 & 0.491 \\
\hline
\end{tabular}


Table 3. Surface concentration (atomic \%) of oxygen, sulfur and phosphorus species obtained by fitting the O1s, S2p and P2p core level peals of XPS spectra.

\begin{tabular}{lcccccc}
\hline & $\mathrm{C} 1$ & $\mathrm{C} 1 \mathrm{P}$ & $\mathrm{C} 1 \mathrm{~A}$ & $\mathrm{C} 2$ & $\mathrm{C} 2 \mathrm{P}$ & $\mathrm{C} 2 \mathrm{PA}$ \\
\hline $\mathrm{O} 1$ & & 1.43 & 0.44 & 0.5 & & 0.38 \\
$\mathrm{O} 2$ & 1.68 & 0.34 & & 0.82 & 1.62 & 0.39 \\
$\mathrm{O} 3$ & 4.76 & & 2.45 & 0.46 & & \\
$\mathrm{O} 4$ & 0.95 & 0.93 & 1.7 & 1.05 & 2.49 & 2.21 \\
$\mathrm{~S}(\mathrm{O})$ & & 0.16 & 0.31 & 0.79 & 1.17 & 1.48 \\
$\mathrm{O}=\mathrm{P}$ & & 2 & & & 2.48 & 1.63 \\
$\mathrm{O}-\mathrm{P}$ & & 4.3 & & & 3.49 & 2.55 \\
\hline $\mathrm{P} 1$ & & 1.56 & & & 3.06 & 3.29 \\
$\mathrm{P} 2$ & & 0.24 & & & 0.19 & 0.38 \\
$\mathrm{P} 3$ & & 0.1 & & & 0.15 & 0.21 \\
\hline $\mathrm{S} 1$ & 0.15 & 0.28 & 0.5 & 1.51 & 1.16 & 2.37 \\
$\mathrm{~S} 2$ & & 0.08 & 0.08 & 0.37 & 0.38 & 0.74 \\
S3 & & 0.03 & 0.07 & 0.18 & 0.21 & 0.24 \\
S4 & & 0.03 & & 0.01 & 0.34 & 0.06 \\
S5 & 0.15 & 0.05 & 0.07 & 0.12 & 0.14 & 0.21 \\
\hline
\end{tabular}




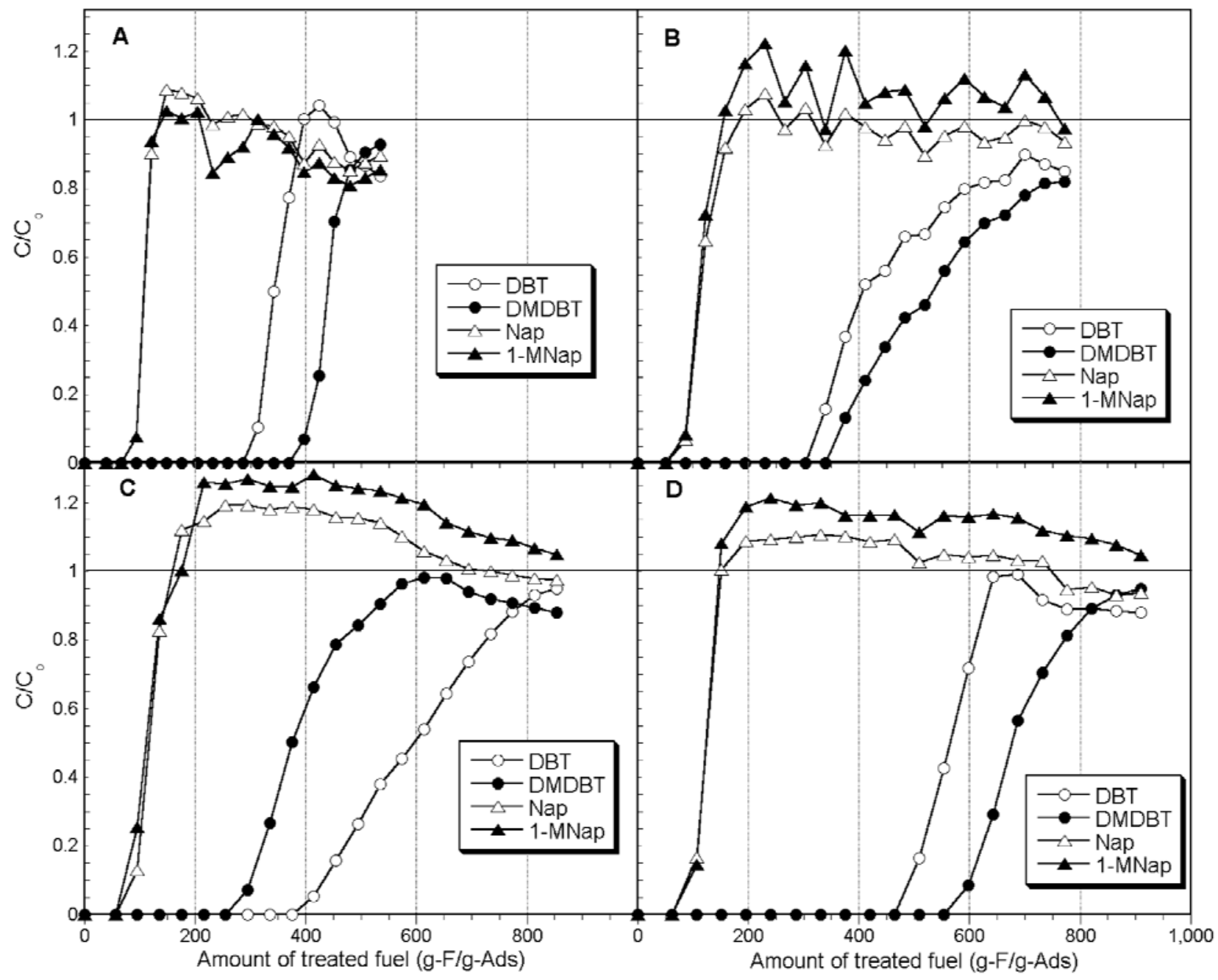

Figure 1. 


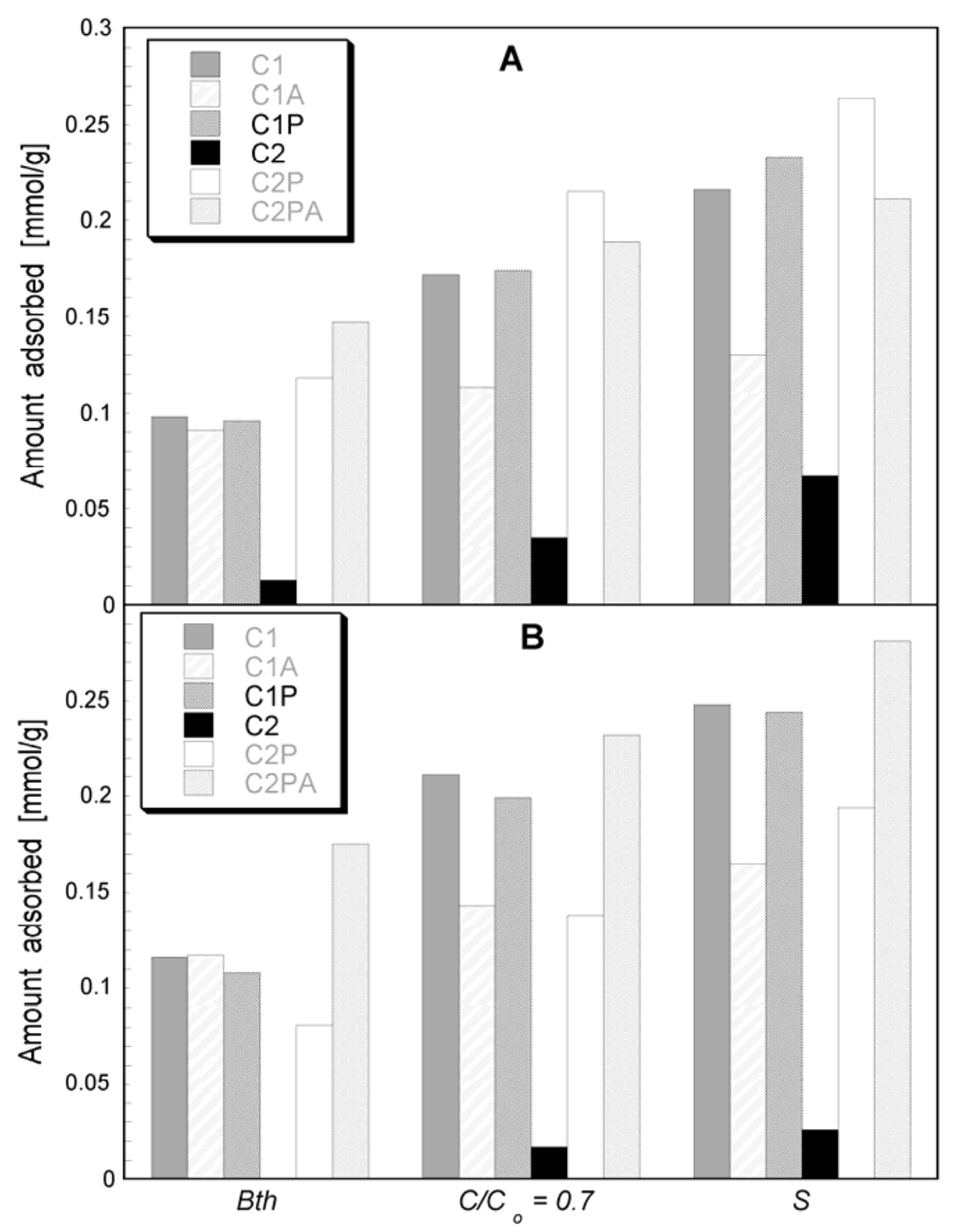

Figure 2. 


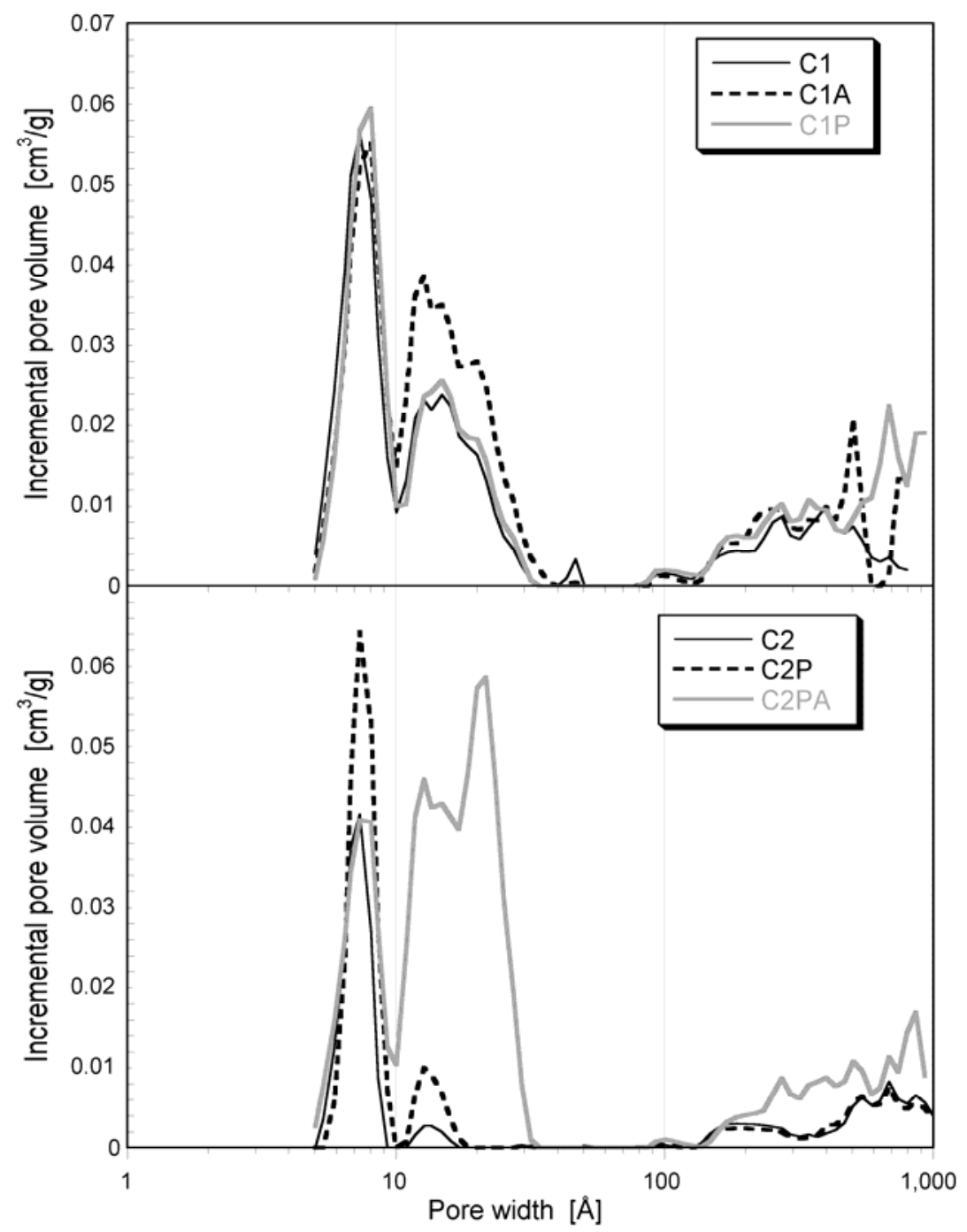

Figure 3. 

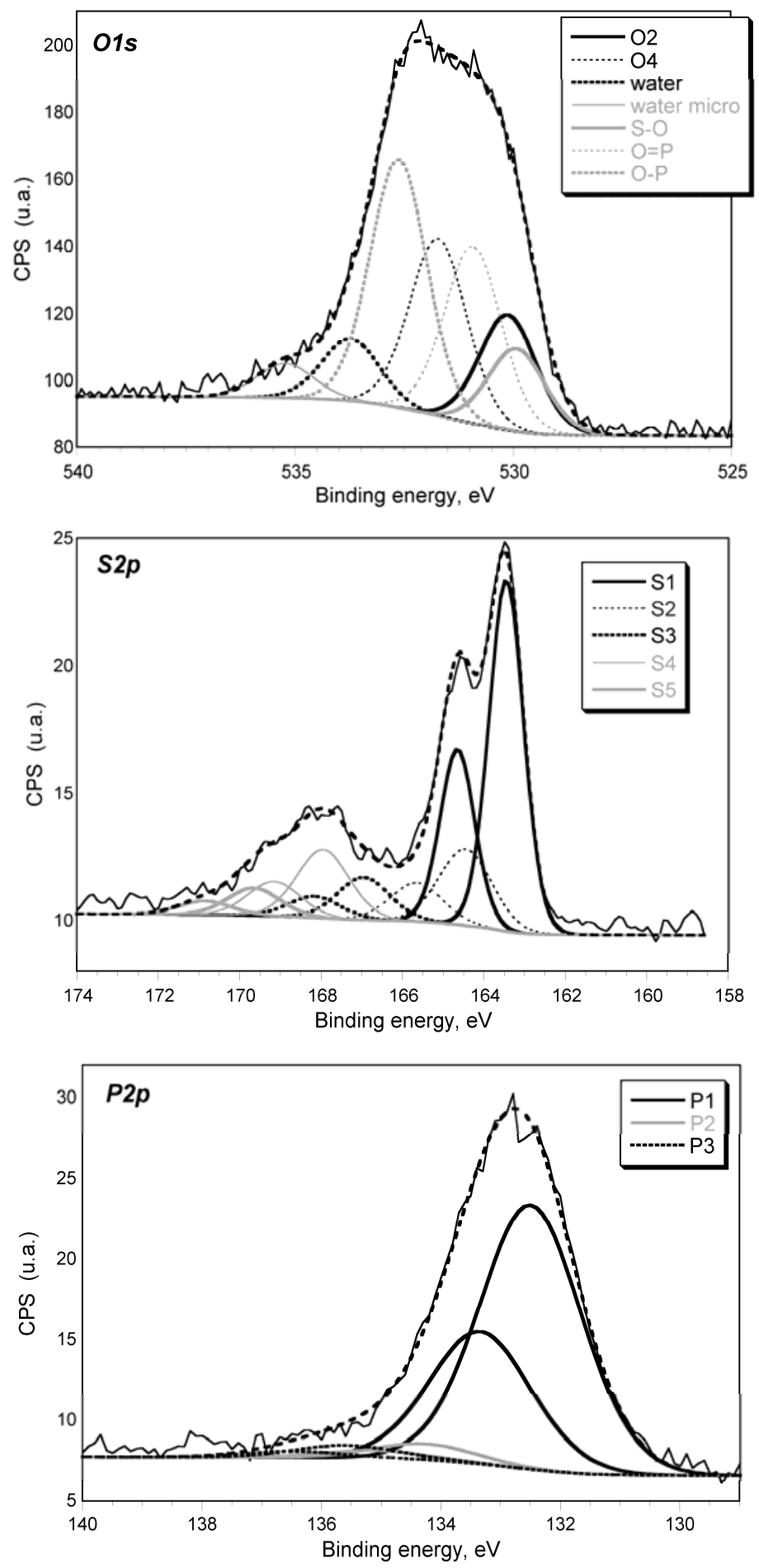

Figure 4. 


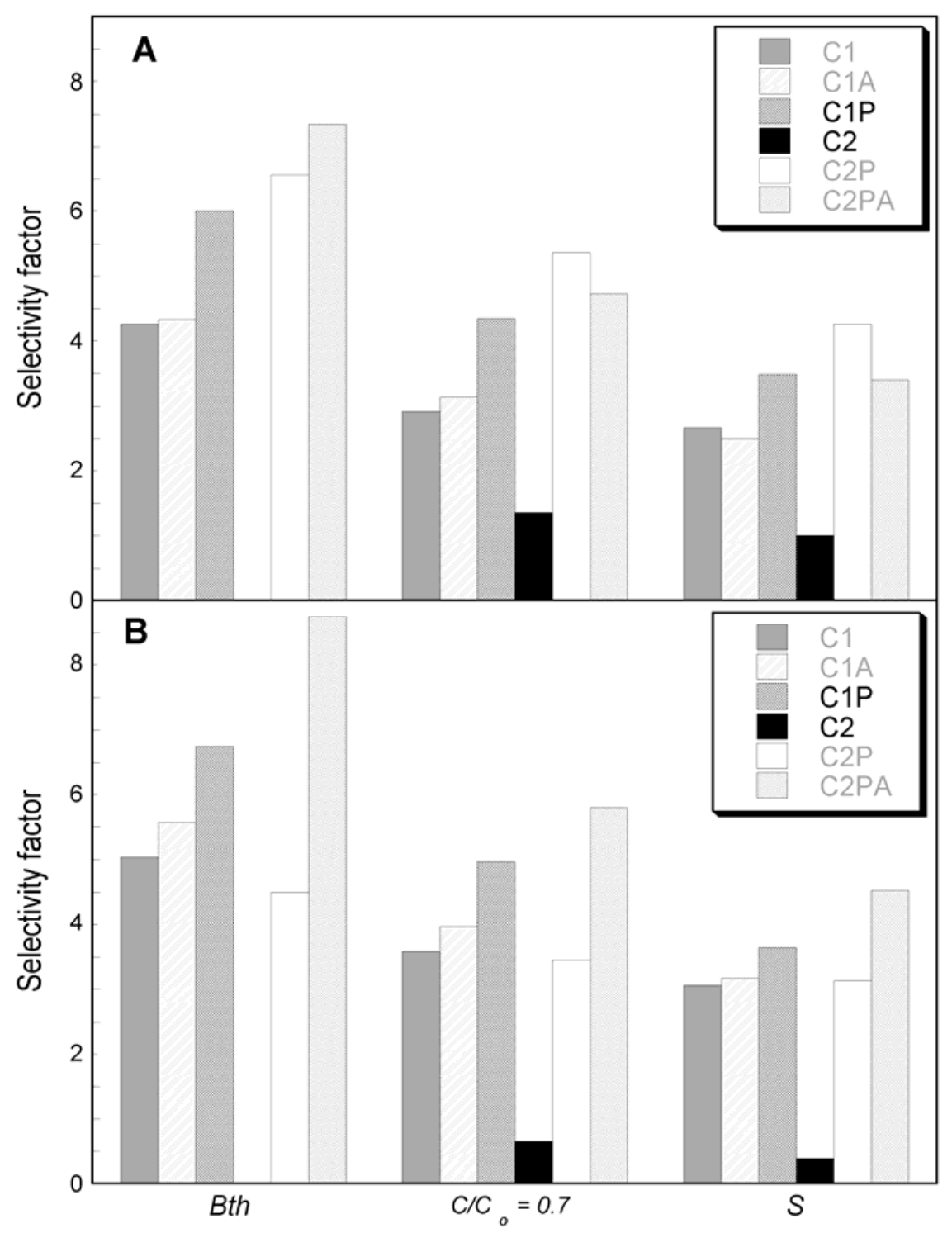

Figure 5. 


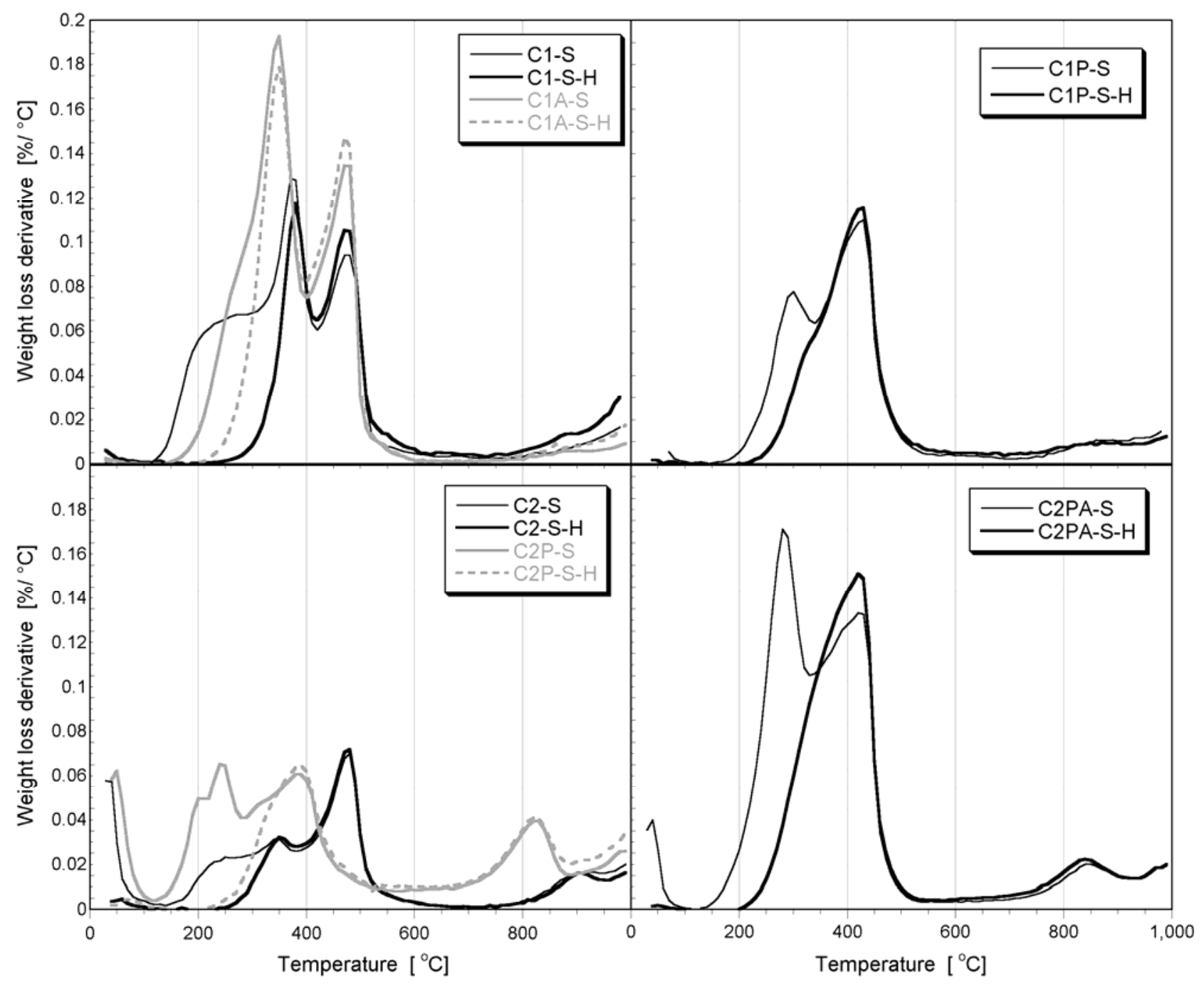

Figure 6. 